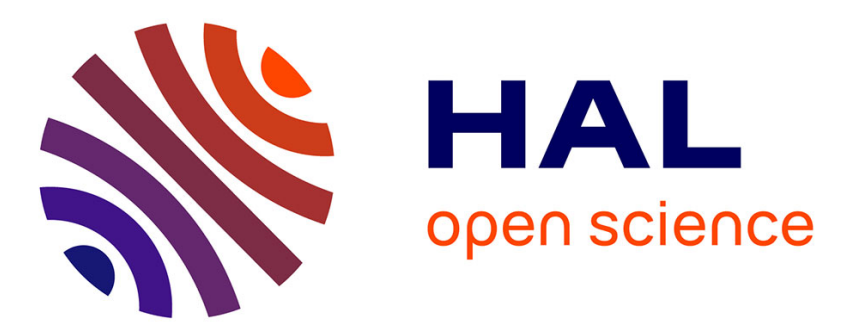

\title{
Litigation in arthroscopic surgery: a 20-year analysis of legal actions in France
}

Charles Pioger, Christophe Jacquet, Alexandre Abitan, Guillaume-Anthony

Odri, Matthieu Ollivier, Bertrand Sonnery-Cottet, Philippe Boisrenoult, Nicolas Pujol

\section{To cite this version:}

Charles Pioger, Christophe Jacquet, Alexandre Abitan, Guillaume-Anthony Odri, Matthieu Ollivier, et al.. Litigation in arthroscopic surgery: a 20-year analysis of legal actions in France. Knee Surgery, Sports Traumatology, Arthroscopy, In press, 10.1007/s00167-020-06182-3 . hal-03176956

\section{HAL Id: hal-03176956 https://hal.science/hal-03176956}

Submitted on 6 Apr 2021

HAL is a multi-disciplinary open access archive for the deposit and dissemination of scientific research documents, whether they are published or not. The documents may come from teaching and research institutions in France or abroad, or from public or private research centers.
L'archive ouverte pluridisciplinaire HAL, est destinée au dépôt et à la diffusion de documents scientifiques de niveau recherche, publiés ou non, émanant des établissements d'enseignement et de recherche français ou étrangers, des laboratoires publics ou privés. 


\title{
Litigation in arthroscopic surgery: a 20-year analysis of legal actions in France
}

\author{
Charles Pioger ${ }^{1} \cdot$ Christophe Jacquet $^{1,3} \cdot$ Alexandre Abitan $^{1} \cdot$ Guillaume-Anthony Odri ${ }^{2} \cdot$ Matthieu Ollivier $^{3}$. \\ Bertrand Sonnery-Cottet ${ }^{4} \cdot$ Philippe Boisrenoult ${ }^{1} \cdot$ Nicolas Pujol $^{1}$ (I)
}

\begin{abstract}
Purpose The main objective of this study was to identify the epidemiological characteristics of litigation following arthro-scopic procedures, performed in private practice and public hospitals in France. The secondary objective was to establish a risk profile for medical malpractice lawsuits after arthroscopic surgery.

Methods All court decisions related to arthroscopic surgery between 1994 and 2020 were collected and reviewed cases from the two main French legal databases (Legifrance and Doctrine). Data were retrospectively collected and included: gender, joint and defendant's specialty involved, reason behind the lawsuit, initial indication and the type of arthroscopic procedure performed. The final verdicts as well as the indemnity awarded to the plaintiff (if any) were recorded.

Results One-hundred eighty cases met the inclusion criteria of the study and were analyzed: 58 cases were before administrative courts and 122 were before civil courts. An orthopaedic surgeon was involved alone or in solidum in $45.6 \%$ of cases $(82 / 180)$, followed by anesthesiologists in $5.6 \%$ (10/180). The private surgery center or public hospital were implicated in 63.9\% (115/180) of cases. The 2 most common joints involved in litigation following arthroscopic surgery were the knee $(82.2 \%, n=148)$ and the shoulder $(11.1 \%, n=20)$. The main reasons behind the lawsuit were related to postoperative infection in 78/180 cases and to a musculoskeletal complication in 45/180 cases (25\%). A failure to inform was also reported in $34 / 180$ cases (18.9\%). Of the 180 cases, 122 cases $(67.8 \%)$ resulted in a verdict for the plaintiff. The average indemnity award for the plaintiff was 77.984 euros [2.282-1.117.667]. A verdict for the plaintiff was significantly associated with postoperative infection or a wrong-side surgery, while technical error and musculoskeletal complications were more significantly likely to result in a verdict in favor of the defendant $(p=0.003)$.

Conclusion This study evaluated and mapped lawsuits following after arthroscopic surgery in France over a period of more than 20 years. The main joint involved in lawsuits was knee. The main causes of lawsuits following arthroscopic surgery were related to postoperative infection, musculoskeletal complications and failure to inform.

Level of Evidence Level IV.
\end{abstract}

Keywords Litigation $\cdot$ Arthroscopy $\cdot$ Indemnity $\cdot$ France $\cdot$ Surgery

\section{Introduction}

Technological advances and increased specialization have led to more ethical and personalized surgery [4]. In parallel, patient information and demands have markedly increased, and questioning the actors of the health care system became more common [11]. In France and among many surgical specialties, orthopaedics is the most subject to lawsuits. On average, an orthopaedic surgeon faces 17 lawsuits in a career [23, 26]. Similarly, Jena et al. [16] reported that orthopaedic surgeons were exposed to an annual risk of lawsuits that 
doubled (14\% vs. $7 \%)$ compared to other medical and surgical specialties.

The number of arthroscopic procedures performed each year is steadily increasing [12]. This significant increase can be explained in part by the development of reliable techniques for procedures that are now common $[7,20]$ but also by the progress of the industry. New joints such as the hip [8], wrist and ankle have become accessible to arthroscopy. Although arthroscopic surgery is considered a safe procedure with easy postoperative recovery period, because it is minimally invasive, it represents a major source of potential malpractice claims against surgeons [25]. Many complications may occur after arthroscopic surgery and be detrimental to the patient's functional prognosis [24, 27]. While diagnostic or wrong-side surgery should be prevented [22], other complications such as infection or the lack of clinical benefit remain inherent to any surgery and lead the patient to file a claim. In France, two recent epidemiological studies have examined the rate of medical malpractice claims in orthopaedic and trauma surgery departments, but neither has specifically focused on arthroscopic surgery [2, 23].

The main objective of this study was to identify the epidemiological characteristics of litigation following arthroscopic procedures, performed in private practice and public hospitals in France. The secondary objective was to establish a risk profile for medical malpractice lawsuits after arthroscopic surgery. It was hypothesized that the knee is the joint most often involved.

\section{Materials and methods}

\section{Legal data source}

Legal arthroscopic cases from the two main French legal databases (Legifrance and Doctrine) were analyzed. Legifrance is a public service facility used to broadcast law online and focused on administrative procedures since 1539 . Doctrine is a legal search engine that centralizes all civil and administrative court decisions in France.

All court decisions related to arthroscopic surgery between 1994 and 2020 were collected and reviewed. The legal cases, anonymized, included decisions of administrative courts and administrative courts of appeal for arthroscopic procedures performed in public hospitals and cases before civil courts and civil courts of appeal concerning private practice.

\section{Data collection}

Eligible decisions were identified by applying a search strategy with the following key words: "arthroscopy" or "arthroscopic" and "medical malpractice". This search was performed by four orthopaedic surgeons: two residents and two senior surgeons including one medical expert. In addition, a legal review was carried out by a lawyer to ensure the relevance and correct collection of cases eligible for inclusion.

Data were retrospectively collected in a computerized file and included: gender, date of the triggering event, date before the first instance court and of the appeal (if applicable), the reference of the decision, the joint and the defendant's specialty involved, as well as the city in which the appeal was filed. In addition, the initial indication and the type of arthroscopic procedure performed were recorded. The age of the patient was not available, as part of the anonymization of the databases.

The data collected on the reasons for lawsuits included: wrong-sided surgery, misdiagnosis, failure to inform, inadequate care, infection, thromboembolic events (deep venous thrombosis or pulmonary embolism), cardiovascular, musculoskeletal (stiffness, chronic pain, complex regional pain syndrome), neurological, vascular complications and blockrelated to anesthesia or equipment (broken instrument). The possible death of the patient related to arthroscopic procedure was systematically noted. The final verdicts (in favor of the defendant or the plaintiff) as well as the indemnity awarded to the plaintiff (if any) were recorded.

\section{Eligibility criteria}

All court decisions directly related to arthroscopic surgery were considered for study eligibility. Cases of orthopaedic surgery other than arthroscopic procedures and arthroscopic surgery indirectly related to the cause of action were excluded. Similarly, all interim decisions involving only the appointment of an expert were excluded.

\section{Statistical analysis}

All data were analyzed using JMP11.0 software (SAS Institute $^{\circ}$ ). As the numerical data did not have a normal distribution, non-parametric analyses were performed (Wilcoxon tests). Comparison of qualitative data was performed using the Fisher test. The alpha threshold of 5\% was chosen.

This study was approved by the institutional review board of the hospital and by the scientific committee of our institution. This study was performed in accordance with the ethical standards outlined in the 1964 Declaration of Helsinki. All patient data were all anonymized in the above-mentioned databases. 


\section{Results}

\section{Cases characteristics}

Seventy-one lawsuits from the Legifrance database and 687 from the Doctrine database could be identified. After removal of duplicates, 180 cases met the inclusion criteria of the study and were analyzed: 58 cases were before administrative courts and 122 were before civil courts (Fig. 1). Five cases were identified in the period 1994-1999, 59 in the period 2000-2009 and 116 in the period 2010-2020. Among the included cases, 119 (66.1\%) involved male plaintiffs. The median time between the triggering event and verdict of the first instance court was 6.4 years [0.8-36.9]. An appeal was filed, in $60.6 \%$ of cases $(n=109)$ with a median time between the triggering event and the appeal of 8.6 years [2.7-38.7] (Fig. 1).

Regarding the distribution of defendants, an orthopaedic surgeon was involved alone or in solidum in $45.6 \%$ of cases (82/180), followed by anesthesiologists in 5.6\% (10/180). The private surgery center or public hospital were implicated in $63.9 \%(115 / 180)$. A specific public solidarity fund managed by the National Office for the Indemnification of Medical Accidents (ONIAM) was implicated in $3.3 \%$ of cases (6/180). While one case also involved two other specialties (rheumatologist and family medicine), a second involved a company specializing in implantable orthopaedic devices. (Table 1).
Table 1 Distribution of defendants involved in the malpractice lawsuit following arthroscopic procedure

\begin{tabular}{ll}
\hline Defendants & Cases $(n=180)$ \\
\hline Private or public surgery center $(\mathrm{C}), n(\%)$ & $86(47.8)$ \\
Orthopaedic surgeon $(\mathrm{O}), n(\%)$ & $53(29.4)$ \\
O+C in solidum, $n(\%)$ & $23(12.8)$ \\
ONIAM, $n(\%)$ & $5(3.3)$ \\
Anesthesiologist (A), $n(\%)$ & $4(2.2)$ \\
A+C in solidum, $n(\%)$ & $3(1.7)$ \\
O+A+C in solidum, $n(\%)$ & $3(1.7)$ \\
O+ONIAM, $n(\%)$ & $1(0.6)$ \\
O+Rheumatologist, $n(\%)$ & $1(0.6)$ \\
O+ Medical device company, $n(\%)$ & $1(0.6)$ \\
\hline
\end{tabular}

Of the 180 cases, 122 cases $(67.8 \%)$ resulted in a verdict for the plaintiff. Three lawsuits were a result of patient death and only one led to a verdict in favor of the plaintiffs. The average indemnity award for plaintiff verdicts was 77.984 euros [2.282-1.117.667].

The distribution of the cases by joint is summarized in Fig. 2. The 2 most common joints involved in litigation following arthroscopic surgery were the knee $(n=148,82.2 \%)$ and the shoulder $(n=20,11.1 \%)$. Regarding the knee joint, lawsuits were related to either the management of a meniscal tear in $66 / 148$ cases $(44.6 \%$ ) or anterior cruciate ligament (ACL) surgery in 34 cases (23\%). The distribution of cases according to the diagnosis is presented in Table 2.
Fig. 1 Flowchart of lawsuits after arthroscopic procedures. $n$ number, $A C$ Administrative court, ACA Administrative court of appeal, $C C$ Civil court, CCA Civil court of appeal
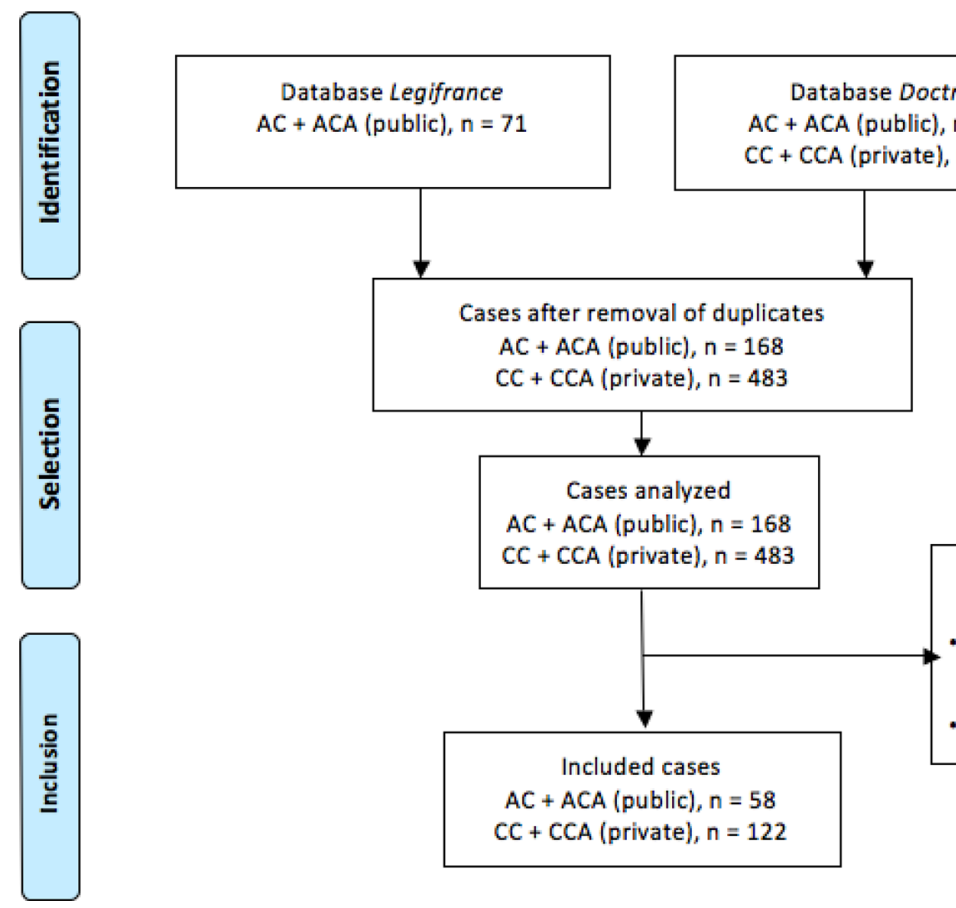

Excluded cases ( $n=471$ )

No direct link between lawsuit and arthroscopic surgery

Appointment of an expert 
Fig. 2 Distribution of malpractice cases for each joint after arthroscopic surgery

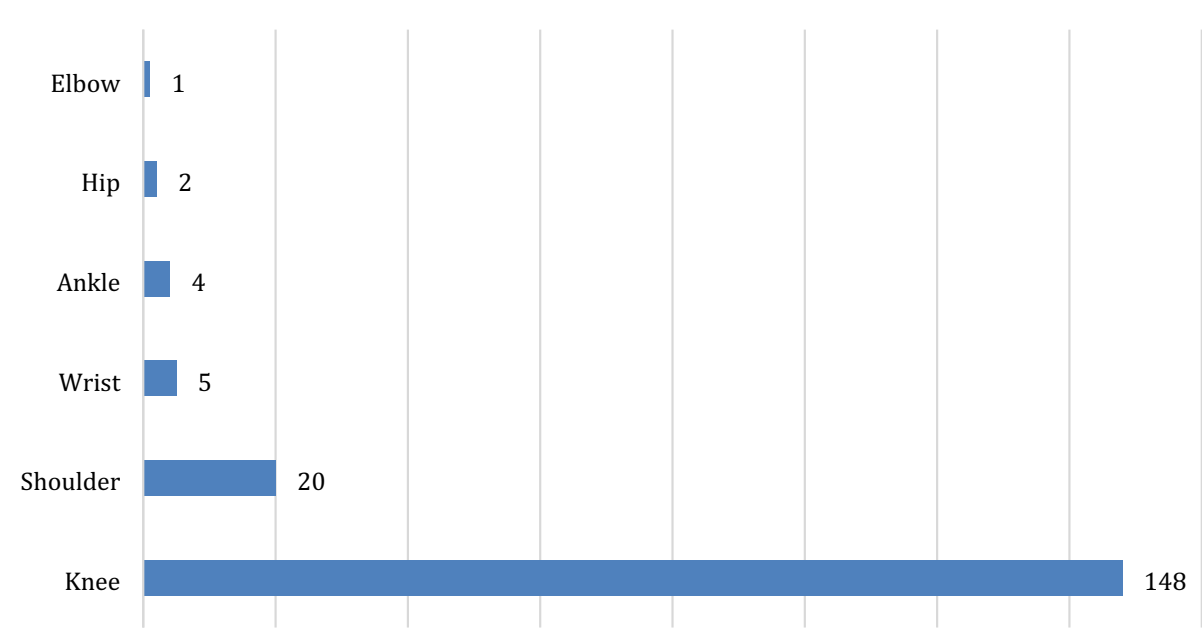

Table 2 Distribution of cases by diagnosis

\begin{tabular}{ll}
\hline Diagnosis & Cases $(n=180)$ \\
\hline Knee, $\mathrm{n}(\%)$ & $/ 148$ \\
Meniscal tears & $66(44.6)$ \\
CL rupture & $34(23.0)$ \\
Stiffness & $5(3.4)$ \\
Others & $17(11.5)$ \\
No diagnosis & $25(16.9)$ \\
Shoulder, $\mathrm{n}(\%)$ & $/ 20$ \\
Shoulder rotator cuff injuries & $7(35.0)$ \\
Subacromial impingement & $7(35.0)$ \\
Acromioclavicular Disjunction & $2(10.0)$ \\
Instability & $2(10.0)$ \\
No diagnosis & $2(10.0)$ \\
Wrist, $\mathrm{n}(\%)$ & $/ 5$ \\
Endoscopic Neurolysis & $2(40.0)$ \\
Traumatology & $2(40.0)$ \\
Tenosynovitis & $1(20.0)$ \\
Ankle, $\mathrm{n}(\%)$ & $/ 4$ \\
Anterior impingement & $4(100)$ \\
Hip, n $(\%)$ & $/ 2$ \\
Femoroacetabular Impingement & $1(50.0)$ \\
No diagnosis & $1(50.0)$ \\
Elbow, $\mathrm{n}(\%)$ & $/ 1$ \\
Stiffness & $1(100)$ \\
\hline
\end{tabular}

The reasons behind the lawsuit were related to postoperative infection in 78/180 cases (43.3\%), musculoskeletal complication (stiffness, chronic pain, complex regional pain syndrome) in $45 / 180$ cases ( $25 \%$ ). A failure to inform was reported in 34 out of 180 cases (18.9\%). The complete distribution of reasons for lawsuit is summarized in Fig. 3.

A comparison between civil and administrative procedure was carried out and reported in Table 3. With respect to the reasons behind the lawsuit, failure to inform and postoperative infection were significantly associated with civil procedures, while litigation for technical error was reported significantly more frequently among administrative procedures.

No significant difference was observed between these two groups concerning the distribution of cases according to the joint involved or the diagnosis. Similarly, no difference was found with respect to the other reasons for lawsuits between administrative and civil procedure.

The rate of verdict in favor of the plaintiff was significantly higher in the civil procedure $(76.8 \%)$ than in the administrative procedure (48.4\%) $(p=0.0006)$. However, the average indemnity award was comparable between civil and administrative procedure, with, respectively, 79,985 euros [2.282-576.882] vs. 77.381 euros [800-1.117.667].

\section{Statistical correlation analysis}

(a) Correlation between reason for lawsuit and verdict: In cases where musculoskeletal complication was the reason for the lawsuit, $48.9 \%$ of the verdicts were in favor of the plaintiff $(p=0.003)$. When technical error was invoked, $27.3 \%$ of the verdicts were in favor of the plaintiff $(p=0.003)$. Conversely, for postoperative infection, $87.2 \%$ of the verdicts were in favor of the plaintiff and $100 \%$ when a wrong-side surgery was the complaint. Consequently, a verdict for the plaintiff was significantly associated with postoperative infection or a wrong-side surgery, while technical error and musculoskeletal complications were more significantly likely to result in a verdict in favor of the defendant. Among the other reasons, no statistically significant correlation was observed.

(b) Correlation between reason behind lawsuit and indemnity payment: The average indemnity award for plaintiff verdict was significantly higher when the reason for lawsuit was a neurological complication compared to 
Fig. 3 Reasons for lawsuit following arthroscopic procedures

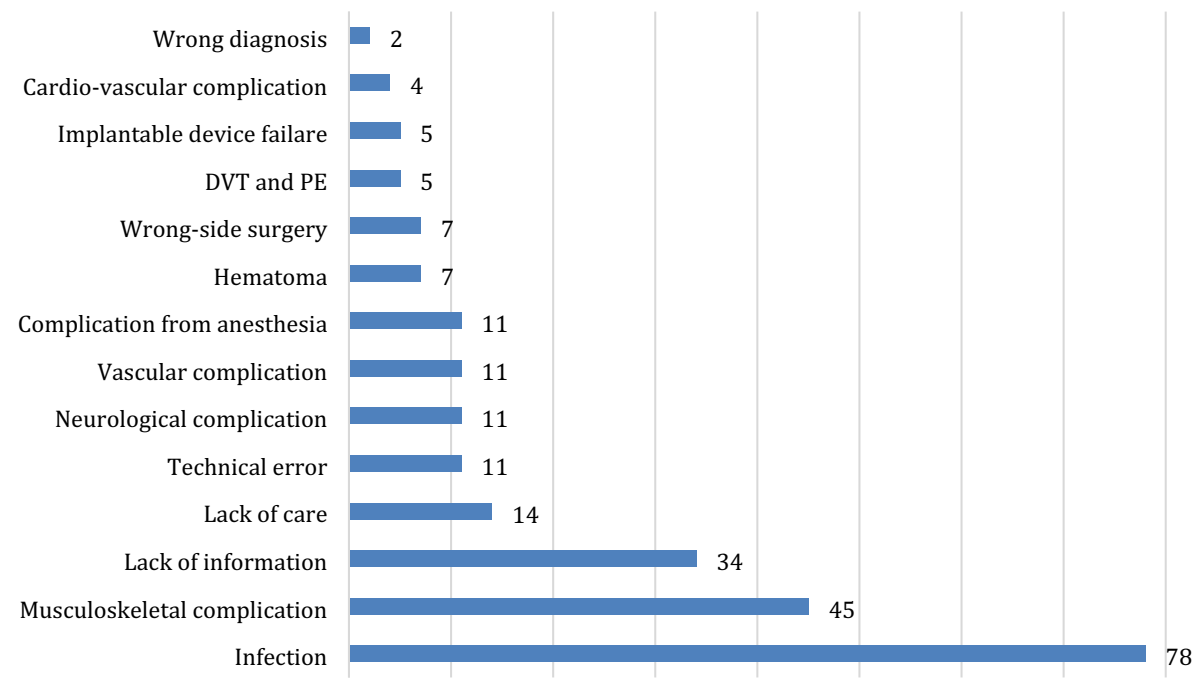

Table 3 Comparison between administrative procedure (public practice) and civil procedure (private practice) other reasons $(p=0.045)$. Similarly, wrong-side surgery was significantly associated with a lower indemnity payment compared to other reasons $(p=0.0004)$.

(c) Correlation between reason behind lawsuit and knee/ shoulder joints: A significantly higher percentage of claims for infection was observed after knee arthroscopies $(n=72 / 148,48.6 \%)$ compared to shoulder arthroscopies $(n=3 / 20,15 \%)(p=0.004)$. No significant difference was found for the other reasons.
Administrative procedure $(n=58) \quad$ Civil procedure $(n=122) \quad P$ value

Gender, $n$
Women

Time between triggering event and verdict (in years)

Appeal (\%)

Reason behind lawsuit (\%)

Technical error

Failure to inform

Orthopaedic surgeon

Verdict in favor of plaintiff (\%)

*Fisher test, **Wilcoxon test, $n . s$ non-significant
Indemnity payment (euros)

40

18

$5.6[0.8-36.9]$

13.8

29.3

6.9

1.7

0

96.6

48.4

79985 [2282-576 882] (n.s)*

79

43

$6.65[1.3-23.1]$

$(\mathrm{n} . \mathrm{s})^{* *}$

39.3

$(\mathrm{n} . \mathrm{s})^{*}$

2.5

$0.006^{*}$

$0.01 *$

$0.004^{*}$

24.6

$<0.0001 *$

$0.03 *$

$<0.001 *$

$0.0006^{*}$

76.2

77,381 [800-1 117 667] (n.s)**

\begin{tabular}{cc}
66.4 & $<0.0001^{*}$ \\
8.2 & $0.03^{*}$ \\
48.4 & $<0.001^{*}$ \\
76.2 & $0.0006^{*}$ \\
$77,381[800-1117667]$ & $(\text { n.s) })^{* *}$ \\
\hline
\end{tabular}

(2)

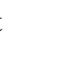


of an infection (septic arthritis or surgical site) was the most reported reason behind the lawsuit, ahead of musculoskeletal complications (stiffness, chronic pain, unsatisfactory result) and failure to inform. A defense verdict was observed in a significantly higher proportion in private practice. Similarly, the risk of a malpractice claim for failure to inform was four times higher in private practice than in public hospitals. Another finding was that the average award amount for the cases with a verdict for the plaintiff was significantly higher when the reason for the lawsuit was a neurological complication.

In our study, the average indemnity amount for cases that had a verdict for the plaintiff ( $€ 77.984$ ) have been reported to be well below the average damage award in the United States, which is close to 1 million euros (€932.000) [25]. A recent study on the malpractice claims in orthopaedic traumatology in a public hospital department have reported an average compensation to the plaintiff of 79.497 euros, which is similar to the compensations in our lawsuit [2]. These values were close to those found by Tarantino et al. in Italy but lower than in England (respectively, 71.524 euros and $>115.615$ euros) $[3,28]$. Moreover, Shah et al. [25] reported that, in the United States, the plaintiffs' claims have been granted in only $26 \%$ compared to $67.8 \%$ in our study.

There was a high number of infection cases $(43.3 \%$, $78 / 180$ cases), similar to the infection cases reported after arthroplasty or trauma surgery in France [2]. Conversely, Shah et al. [25] showed that about $15 \%$ of complaints following arthroscopic procedures were related to postoperative infection in the United States. Musculoskeletal complications were indeed more frequent in their series of 240 cases, but infection remained the leading cause of legal action after knee arthroscopy, which corroborates the results presented in our study. Marmor et al. [21] reported a paradoxically higher proportion of lawsuits for septic arthritis after arthroscopy (42\%) than after arthroplasty (27\%) after analysis of insurance data. The authors identified several risk factors such as irrelevant indications (especially diagnostic arthroscopy) and also the use of intraoperative corticosteroids, which they advise against $[6,15]$. Although 2 cases of septic arthritis after corticosteroid injection during an arthroscopy were observed in our series of cases, there were 13 cases of septic arthritis after diagnostic arthroscopy or arthroscopic lavage.

Another frequently cited reason for filing a lawsuit was the failure to inform. As Mouton et al. [23] pointed out in their analysis of orthopaedic litigation in four university hospitals, the doctor-patient relationship is significantly questioned and remains an avenue of reflection to prevent legal recourse. In our study, the plaintiff invoked a failure to inform, follow-up or care in 1 case out of 5. However, it has been shown that effective communication with a clear explanation of the complications and benefits limits the risk of litigation $[1,3,18]$. Over the years, case law has only reinforced the surgeon's duty to inform the patient; the surgeon must ensure that the patient fully understands and must be able to prove that he has correctly informed his patient $[10$, 13, 14]. Similarly to the failure to inform or misdiagnosis claims, lawsuits for wrong-site surgery is avoidable $[9,17$, 19]. We found this malpractice claim in almost $4 \%$ of the cases in our study, and they systematically lead to compensation in favor of the plaintiff. In a recent editorial, Mark D. Miller emphasized that wrong-site surgery should never happen again and called for surgeons' vigilance and mentioning the benefit of the "Sign Your Site" campaign of the American Academy of Orthopedic Surgeons [22].

Regarding the knee joint, lawsuits were most frequently related to either the management of a meniscal tear $(66 / 180$, $44.6 \%$ ) or anterior cruciate ligament (ACL) surgery (23\%). Bokshan et al. [5] evaluated the risk factors for litigation after ACL reconstruction and pointed out that $63 \%$ of lawsuits did not involve technical errors (malpositioning of the graft, screws) but occurred mainly after postoperative infection (septic arthritis), persistent pain or limited range of motion. Similarly, we observed a significant incidence of septic arthritis secondary to ACL reconstruction in more than half of the cases. However, the surgeon's responsibility after the infection cases was only called into question if there was a delay in diagnosis or treatment of the infection that did not comply with the recommendations. This result can be explained by the specific system of compensation after care in France, which, except in the event of a lack of prevention, diagnosis or care on the part of the practitioner, charges the establishment with compensation for the damage. (ref Legifrance) Nevertheless, information on the septic risk after arthroscopy must be reinforced.

The limitations of our study included the use of legal databases whose exhaustiveness has not been proven. However, it is likely that the substantial number of cases reported over a period of more than 20 years is a representative sample of legal cases after arthroscopy. On the other hand, these data concerned complaints resulting in a decision by a civil or administrative court and excluded other means of claims in France: insurance settlements, amicable recourse, conciliation and compensation procedures related to the specific public solidarity fund (ONIAM), without secondary legal recourse. It is, therefore, possible that the cases presented do not reflect the true distribution of the various causes of medical malpractice claim after arthroscopy in France. Another weakness of the study was the anonymization of the data provided by the databases, which did not allow us to assess litigation according to the demographic and socio-economic characteristics of patients.

This study highlighted the significant prevalence of litigation in arthroscopic practice. These findings are useful to enable appropriate delivered preoperative information 
for clinicians when arthroscopic procedure is necessary, to decrease the rate of malpractice claims.

\section{Conclusion}

This study evaluated and mapped lawsuits following arthroscopic surgery over a period of more than 20 years. The main source of lawsuits was knee arthroscopy, particularly the management of meniscal tears and anterior cruciate ligament injury. Postoperative infection, musculoskeletal complications and failure to inform were the main causes of litigation after arthroscopy. These results should guide surgeons in providing information to the patient and in the management of a possible complication, to hopefully reduce the number of lawsuits.

Acknowledgements The authors thank the attorneys at law Dana Leib (New York Bar) and Barbara Teissier du Cros (Paris Bar) for their kind help.

Authors' contribution $\mathrm{CP}$ has made substantial contributions to conception, study design, acquisition/interpretation of data and in drafting the manuscript. CJ and AA have made substantial contributions to acquisition of data. GO was in charge of the statistical analysis. MO, $\mathrm{PB}, \mathrm{BSC}$ and NP have been involved in drafting or revising the manuscript critically. Each author has given final approval of the version to be published and agrees to be accountable for all aspects of the work in ensuring that questions related to the accuracy or integrity of any part of the work are appropriately investigated and resolved.

Funding No benefits in any form have been received or will be received related directly or indirectly to the subject of this article.

\section{Compliance with ethical standards}

Conflict of interest $\mathrm{CP}, \mathrm{CJ}, \mathrm{AA}, \mathrm{PB}$ and GO have nothing to disclose. $\mathrm{MO}$ is educational consultant for Stryker and Newclip. BSC is educational consultant and receives royalties from Arthrex. NP is occasional educational consultant for Smith\&Nephew, Lima, ZimmerBiomet, Stryker, outside the scope of this work.

Ethical approval No ethical approval was need for this study.

\section{References}

1. Adamson TE, Tschann JM, Gullion DS, Oppenberg AA (1989) Physician communication skills and malpractice claims. A complex relationship. West J Med 150:356-360

2. Agout C, Rosset P, Druon J, Brilhault J, Favard L (2018) Epidemiology of malpractice claims in the orthopedic and trauma surgery department of a French teaching hospital: a 10-year retrospective study. Orthop Traumatol Surg Res 104:11-15

3. Atrey A, Gupte CM, Corbett SA (2010) Review of successful litigation against english health trusts in the treatment of adults with orthopaedic pathology: clinical governance lessons learned. J Bone Joint Surg Am 92:e36
4. Benson M, Boehler N, Szendroi M, Zagra L, Puget J (2014) Ethical standards for orthopaedic surgeons. Bone Joint $\mathrm{J}$ 96:1130-1132

5. Bokshan SL, Ruttiman R, Eltorai AEM, DePasse JM, Daniels AH, Owens BD (2017) Factors Associated With Physician Loss in Anterior Cruciate Ligament Reconstruction Malpractice Lawsuits. Orthopaedic Journal of Sports Medicine SAGE Publications Inc 5:2325967117738957

6. Cancienne JM, Brockmeier SF, Carson EW, Werner BC (2018) Risk Factors for Infection After shoulder arthroscopy in a large medicare population. Am J Sports Med 46:809-814

7. Colvin AC, Egorova N, Harrison AK, Moskowitz A, Flatow EL (2012) National trends in rotator cuff repair. J Bone Joint Surg Am 94:227-233

8. Colvin AC, Harrast J, Harner C (2012) Trends in hip arthroscopy. J Bone Joint Surg Am 94:e23

9. Coudane H, Danan J-L, Lighezollo Alnot J (2018) Litigation in orthopaedic surgery: new ethical challenges. Orthop Traumatol Surg Res 104:1-2

10. Dugleux E, Rached H, Rougé-Maillart C (2018) Proof of patient information: analysis of 201 judicial decisions. Orthop Traumatol Surg Res 104:289-293

11. Ferrara SD, Baccino E, Bajanowski T, Boscolo-Berto R, Castellano M, De Angel R, Pauliukevičius A, Ricci P, Vanezis P, Vieira DN, Viel G, Villanueva E, EALM Working Group on Medical Malpractice (2013) Malpractice and medical liability. European Guidelines on Methods of Ascertainment and Criteria of Evaluation. Int J Legal Med 127:545-557

12. Garrett WE, Swiontkowski MF, Weinstein JN, Callaghan J, Rosier RN, Berry DJ, Harrast J, Derosa GP (2006) American board of orthopaedic surgery practice of the orthopaedic surgeon: partii, certification examination case mix. J Bone Joint Surg Am 88:660-667

13. Giudici K, Gillois P, Coudane H, Claudot F (2015) Oral information in orthopaedics: how should the patient's understanding be assessed? Orthop Traumatol Surg Res 101:133-135

14. Gleyze P, Coudane H (2016) Patient information in orthopedic and trauma surgery. Fundamental knowledge, legal aspects and practical recommendations. Orthop Traumatol Surg Res 102:S105-111

15. Gosal HS, Jackson AM, Bickerstaff DR (1999) Intra-articular steroids after arthroscopy for osteoarthritis of the knee. J Bone Joint Surg Br 81:952-954

16. Jena AB, Seabury S, Lakdawalla D, Chandra A (2011) Malpractice risk according to physician specialty. N Engl J Med 365:629-636

17. Kibler WB (2017) Value on the front end: making the effective diagnosis for optimal treatment. Arthroscopy 33:493-495

18. Levinson W, Roter DL, Mullooly JP, Dull VT, Frankel RM (1997) Physician-patient communication. The relationship with malpractice claims among primary care physicians and surgeons. JAMA 277:553-559

19. Lubowitz JH, Brand JC, Rossi MJ (2018) Malpractice Litigation After Arthroscopy. Arthroscopy J Arthroscopic Related Surg 34:2009

20. Mall NA, Chalmers PN, Moric M, Tanaka MJ, Cole BJ, Bach BR, Paletta GA (2014) Incidence and trends of anterior cruciate ligament reconstruction in the United States. Am J Sports Med 42:2363-2370

21. Marmor S, Farman T, Lortat-Jacob A (2009) Joint infection after knee arthroscopy: medicolegal aspects. Orthop Traumatol Surg Res 95:278-283

22. Miller MD (2018) editorial commentary: outside the scope of practice-wrong-site surgery should never happen. Arthroscopy $34: 2245-2246$

23. Mouton J, Gauthé R, Ould-Slimane M, Bertiaux S, Putman S, Dujardin F (2018) Litigation in orthopedic surgery: what can we 
do to prevent it? Systematic analysis of 126 legal actions involving four university hospitals in France. Orthop Traumatol Surg Res 104:5-9

24. Salzler MJ, Lin A, Miller CD, Herold S, Irrgang JJ, Harner CD (2014) Complications after arthroscopic knee surgery. Am J Sports Med 42:292-296

25. Shah KN, Eltorai AEM, Perera S, Durand WM, Shantharam G, Owens BD, Daniels AH (2018) Medical malpractice litigation following arthroscopic surgery. Arthroscopy 34:2236-2244

26. Sham (2015) Panorama du risque en établissement de santé sociaux et médico- sociaux, bilan de l'année 2014-2015. http:// www.sham.fr/content/download/15740/85611/version/1/file/ Panorama Sham 2015 synthese.pdf
27. Shin JJ, Popchak AJ, Musahl V, Irrgang JJ, Lin A (2018) Complications after arthroscopic shoulder surgery: a review of the american board of orthopaedic surgery database. J Am Acad Orthop Surg Glob Res Rev 2:e093

28. Tarantino U, Giai Via A, Macrì E, Eramo A, Marino V, Marsella LT (2013) Professional liability in orthopaedics and traumatology in Italy. Clin Orthop Relat Res 471:3349-3357 